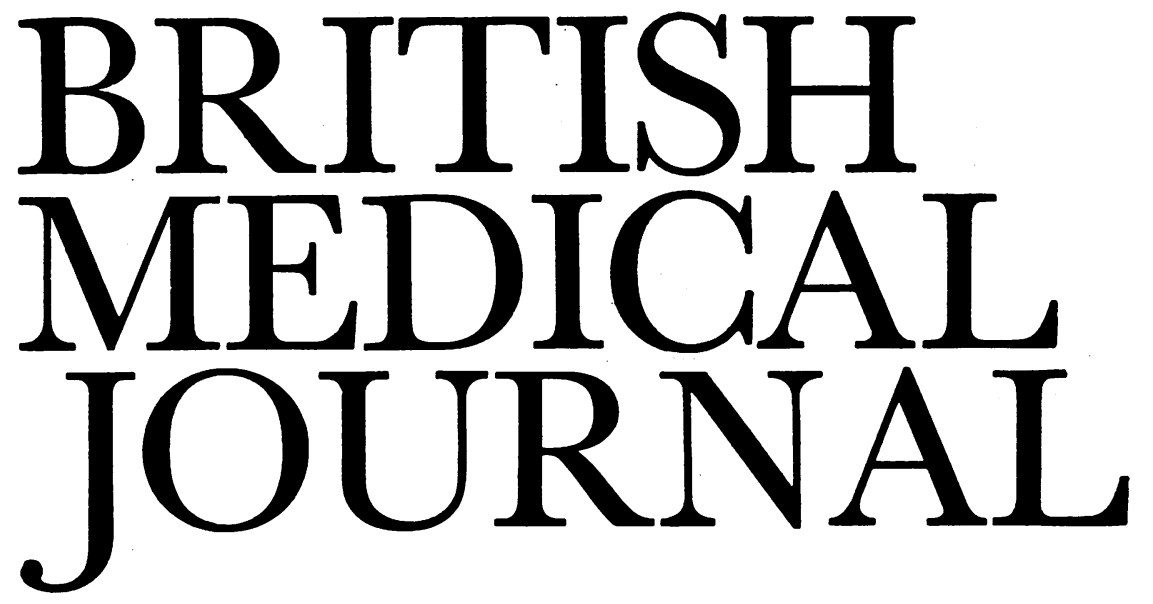

LONDON, SATURDAY 16 MAY 1987

\title{
Ethics committees and research in children
}

There are three main guardians of the ethics of research: the integrity of the investigator, the research ethics committee, and the editorial scrutiny of the journal to which the results are submitted. Research on children places a special responsibility on those who do and monitor research because of children's vulnerability and their inability to give full informed consent (obvious in infants, questionable in older children).

In the past 20 years increasing reliance has been placed on monitoring by research ethics committees, and the Institute of Medical Ethics has recently published a study of their composition and functioning in England and Wales ${ }^{1}$; the survey was part of a wider inquiry into the ethical problems of research in children. ${ }^{2}$ Some of its findings are relevant to the work of all research ethics committees and some specifically to research in children.

Questionnaires were sent to the chairmen of all the 254 research ethics committees identified, and at least partial replies were obtained from $69 \%$. The study thus has all the disadvantages of an inquiry of this kind. The response was incomplete, and the information was limited to what the respondents were prepared to say in reply to an eight page questionnaire. (Most doctors find questionnaires tedious, and in answering them "a man is not upon oath.") Nevertheless, it must be the most broadly based study of research ethics committees in Britain.

The source and extent of the authority of the committees were sometimes not clear, and it was therefore uncertain whether all research proposals in a district would be submitted to them. The size of the committees varied from three members to 41 . Not all had genuine lay members with no affiliation with the institution, and $56 \%$ gave no briefing to new members. Over half the committees had considered some proposals for research on children, but $68 \%$ had no paediatric member and only $29 \%$ had had specific discussions on research in children. More worryingly, a few committees operated in a way that suggested that they did not understand the legal need for informed consent. Proposals for research with children were approved unmodified or with only slight changes in $91 \%$ of cases. There was no evidence that any research on children had been wrongly permitted. One challenging finding was, however, that committees that had a nurse member were less likely to approve without modification proposals for research with children. Surprisingly, having a paediatrician made no such difference.

The study thus provides little evidence that research ethics committees are failing in their main purpose but does show a lack of uniformity and some untidiness in their constitution. Variety is not necessarily bad in committees set up to meet local circumstances, but one of the objectives of the committees is to reassure the public about the way research is carried out-and it is therefore important that they are constituted in a way that achieves this.

The Institute of Medical Ethics makes useful recommendations, ${ }^{2}$ many of which are similar to those made by the Royal College of Physicians, ${ }^{3}$ on the composition and working of research ethics committees. It suggests that a committee should have not fewer than five and not more than 12 members and that these should include a general practitioner, a nurse, and a genuine lay member. It should be accountable to the district health authority or its equivalent, and new members should be briefed and given written guidelines. Informal discussions between chairmen and investigators are welcomed, and chairmen are encouraged to approve proposals with no more than minimal risk without waiting for the full committee to meet.

The recommendation that may cause the most difficulty for the committees is that they should assure themselves of the scientific validity of any proposal. This is hard to dispute since discussing the possible risks and benefits of a research study is pointless if it is scientifically unsound; but a committee chosen to make ethical decisions may not be equally equipped to make scientific judgments. Enlargement of committees may make them ineffective at either. There is a real difficulty here. ${ }^{34}$

The institute gives detailed guidance on research in children: a previous bulletin gave guidelines for deciding what research could reasonably be done in children, ${ }^{5}$ and the more recent booklet advises how committees should consider such proposals. ${ }^{1}$ Though the recommendations do not differ substantially from those of the Royal College of Physicians, they are strengthened by a scholarly discussion of the legal and ethical issues and by the most detailed attempt so far to quantify risks and benefits. ${ }^{2}$

Committees must satisfy themselves that the research project can be done only on children, is scientifically valid, and holds the possibility of considerable benefit to children. They should be sure that the benefits substantially outweigh the risks. Non-therapeutic research on children is justified only if the risks are minimal-that is, if it carries a risk of death of less than one in a million, a risk of a major complication of less than 10 in a million, or a risk of a minor 
complication of less than one in a thousand. (Venepuncture is agreed to carry minimal risk.) Investigators should themselves explain projects to parents, and if the risk is more than minimal they should give a written explanation and time for the parents to consider this. Children aged 7 or over should give their own assent to a procedure-in addition to the necessary consent of the parents. If the child is between 7 and 14 his unwillingness to take part in non-therapeutic research should be binding, but his parents could override his unwillingness to take part in therapeutic research. Over 14 the young person's view should be paramount, though parental consent is still legally required until 16 for therapeutic, and until 18 for non-therapeutic, research.

The institute recommends that a paediatrician or child expert should be present when research on children is being discussed. He should probably be a full member of the committee if proposals for research in children are likely to be considered at most meetings, but committees must remain small enough for their members to take real responsibility.

The responsibility of the investigator for the ethics of his research cannot be emphasised too strongly, and a possible drawback of research ethics committees is that they may appear to relieve the investigator of some of this responsibility. ${ }^{6}$ Submitting an application to the committee should mean that the investigator is entirely happy about the proposed research. If he has doubts he should be able to ask guidance of the committee in a different way.
One of the most difficult subjects is informed consent in controlled trials, particularly in the newborn. ${ }^{7}$ A policy such as that of the Institute of Medical Ethics, which is strict in its requirement for informed consent, may impose a double standard since the committees cannot stop new treatment $c$ being tried in an uncontrolled way. ${ }^{8}$ The institute's reply is that the number of times an innovative treatment may be used on children without it being submitted as a formal research project to a research ethics committee should be limited. This debate continues, ${ }^{9}$ but opinion is likely to move increasingly towards full discussion of all facts with patients or their parents.

ROGER J ROBINSON

Professor of Paediatrics,

United Medical and Dental Schools of Guy's and St Thomas's Hospitals, Guy's Hospital,

London SE1 9RT

1 Institute of Medical Ethics. Research ethics committees. Institute of Medical Ethics Bulletin 1986;18(suppl 2):1-19.

Nicholson RH, ed. Medical research in children: ethics, law, and practice. Oxford: Oxford University Press, 1986.

3 Royal College of Physicians of London. Guidelines on the practice of ethics committees in medical research. London: Royal College of Physicians, 1984.

4 Anonymous. Research on healthy volunteers [Editorial]. Lancet 1986;ii:900-1.

5 Anonymous. Guidelines: medical research with children: ethics, law and practice. Insinue of Medical Ethics Bulletin 1986;14(May):8-9.

Medical Ethics Bulletin 1986;14(May):8-9.
Lewis PJ. The drawbacks of research ethics committees. Joumal of Medical Ethics 1982;8:61-4.

6 Lewis PJ. The drawbacks of research ethics committees. Four

Tarnow-Mordi W. Informed consent. Br Med f 1986;293:562

8 Baum M. Do we need informed consent? Lancet 1986;ii:911-2.

9 Glover J. The MRC and informed consent. Br Med f 1986;293:157-8.

\section{Children, bikes, and money}

Adventurous children injure themselves (and may die) in accidents. In some societies they fall out of trees' ${ }^{1}$; in others they may drown. ${ }^{2}$ In Britain and other Western countries the leading cause of accidental injuries and deaths is road traffic accidents; these account for one quarter of all deaths between the ages of 5 and 14. The resurgence of interest in bicycles in recent years has been accompanied, sadly, by an increase in the numbers of children injured or killed on bikes. ${ }^{3}$ Some at least of these deaths and injuries are preventable.

At $\mathrm{p} 1267$ we publish a detailed study by Nixon $e t$ al from Australia of 891 bicycle accidents over 10 years. Boys had far more accidents than girls, and the peak age was 12-14. Most (32) of the 46 deaths were due to head injuries; in 40 (87\%) the cyclist was in collision with a motor vehicle or a train. A similar study in Philadelphia analysed 520 children injured while riding bikes. ${ }^{4}$ Again more $(72 \%)$ were boys. One third were stunt riding or "riding too fast" at the time of the accident. Only three riders were wearing protective helmets. Most of the injuries were minor and none of the children died-but in the United States around 600 children die each year in bicycle accidents.

What, then, about prevention? Firstly, Nixon et al and the American authors are agreed that fewer children would be injured severely or die if all cyclists wore helmets. Next, cyclists-and especially child cyclists, who are inexperienced, impatient, and adventurous-should be separated from other traffic. They should also be given formal training in road safety; police forces which organise cycling proficiency courses not only teach useful skills but also help improve relations between children and the police. Half the children injured in the Philadelphia series had had no instruction at all on safety or road sense.

The design and marketing of bicycles have changed as they have become more popular. Stunt bikes are advertised on television as play machines, and children given these bikes are encouraged to ride them in a spectacular style. A study in Britain of 100 children injured while on BMX bikes found that no fewer than 40 had been attempting stunts, ${ }^{5}$ a finding in line with evidence from the United States. ${ }^{4}$ These bikes seem less than ideal when used simply for transport: at $p 1259$ we report two cases of teenagers who injured their spines in road accidents which concerned no other vehicles.

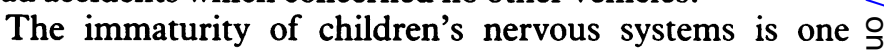
reason for their vulnerability to accidents; and if they are at $N$ risk when using bicycles these risks are even higher when $\rightarrow$ they use motor bikes and "off the road" vehicles. The state- 을 acting as a guardian-forbids children under the statutory ages to drive motor bikes or cars on the highway. Off the road, however, parents may, and do, buy their children vehicles (and for that matter allow them to drink alcohol and 0 play with guns) while unbelievably young.

Parental irresponsibility is one thing; commercial exploitation of that irresponsibility is another. At page 1259 three surgeons from Belfast report serious injuries and one death in children aged 8-15 years riding motorcycles, including both adult bikes and junior scramblers or other vehicles marketed for use "off the road." Some motorcycle clubs organise races for youngsters on bikes of this type.

Experience in the United States has shown that off the road vehicles have become a substantial cause of injuries and 